\title{
Nueva ventana sonográfica para el control del posicionamiento distal del catéter central en neonatos
}

\author{
Viotti F. ${ }^{1}$, Santanera B. ${ }^{1}$, Portela F. ${ }^{1}$, Gerez S. ${ }^{1}$, Venturin N. ${ }^{1}$, Rudzik N. ${ }^{1}$, Acosta CM. ${ }^{1}$ \\ 1 Hospital Privado de Comunidad, Mar del Plata, Argentina.
}

Introducción: La canulación venosa central en neonatos y pacientes pediátricos implica un desafío. Las técnicas guiadas por ultrasonido han permitido realizar este procedimiento con mayor seguridad, reduciendo las complicaciones asociadas. Sin embargo, para verificar la correcta posición del catéter recurrimos a técnicas radiológicas

Reporte de caso: Paciente de 8 días de vida, nacido a termino, $2.800 \mathrm{~g}$ de peso, que presenta atresia de duodenal. Ingresa a quirófano para resolución de su patología por vía videolaparoscopica. Bajo monitorización estándar se realiza inducción con etomidato $0,3 \mathrm{mg} / \mathrm{kg}$ y vecuronio $0,1 \mathrm{mg} / \mathrm{kg}$, seguido de intubación orotraqueal y conexión a ventilación mecánica; mantenimiento con sevofluorano 0,8 CAM, remifentanilo $0,3 \mathrm{mcg} / \mathrm{kg} / \mathrm{min}$, dexmedetomidina 0 , $35 \mathrm{mcg} / \mathrm{kg} / \mathrm{h}$. Se posiciona al paciente para la colocación de acceso vascular central bajo guía ecográfica utilizando sonda lineal HF 6-12MHz (Esaote MyLab Gamma). Se escanea vena braquicefalica izquierda, verificando permeabilidad y se realiza punción en plano, verificando mediante ultrasonido el correcto posicionamiento de la aguja y guía de alambre y se coloca cateter 4 Fr. Un segundo operador utilizando sonda convex 3-6 MHz verifica mediante ventana subxifoidea la posición distal del catéter. Se observa una imagen hiperecoica dentro de la aurícula derecha por lo cual se procede a retirarlo hasta observar el extremo distal en la unión de la vena cava superior con aurícula derecha. Controlada la correcta colocación, se procede a la fijación.

Discusión: Numerosos estudios evidencian que la canulación venosa central ecoguiada constituye un procedimiento seguro y recomendado en neonatos y pacientes pediátricos. Permite no solo evaluar la sonoanatomia, identificar variantes anatómicas y verificar la permeabilidad del vaso; sino también realizar una punción visualizando la aguja, guía de alambre y catéter dentro de la vena en tiempo real. Sin embargo, sobretodo en catéteres que permanecerán un período prolongado, es importante observar la posición del extremo distal del catéter. En este reporte de caso mostramos la posibilidad de verificar de una manera simple a través de una ventana subxifoidea la correcta posición distal del catéter en vena cava superior, sin necesidad de recurrir a la radioscopia o radiografía de tórax. Esta última técnica cuenta con múltiples desventajas: requiere la realización de radioscopia durante el intra-operatorio o el traslado del paciente al departamento de imágenes, además de la exposición a radiación que conlleva y los costos mayores que genera.

El abordaje subxifoideo permite de manera no invasiva y sin radiación verificar la posición distal del catéter. Son necesarios estudios para demostrar el beneficio de este abordaje.

https://doi.org/10.25237/congresoclasa2019.41 